AperTO - Archivio Istituzionale Open Access dell'Università di Torino

\title{
Importance of inverse correlation between ALDH3A1 and PPARgamma in tumor cells and tissue regeneration
}

\section{This is the author's manuscript}

Original Citation:

Availability:

This version is available http://hdl.handle.net/2318/133088

since 2016-10-04T12:50:39Z

Published version:

DOI:10.1016/j.cbi.2011.01.011

Terms of use:

Open Access

Anyone can freely access the full text of works made available as "Open Access". Works made available under a Creative Commons license can be used according to the terms and conditions of said license. Use of all other works requires consent of the right holder (author or publisher) if not exempted from copyright protection by the applicable law. 
This Accepted Author Manuscript (AAM) is copyrighted and published by Elsevier. It is posted here by agreement between Elsevier and the University of Turin. Changes resulting from the publishing process - such as editing, corrections, structural formatting, and other quality control mechanisms - may not be reflected in this version of the text. The definitive version of the text was subsequently published in CHEMICO-BIOLOGICAL

INTERACTIONS, 191 (1-3), 2011, 10.1016/j.cbi.2011.01.011.

You may download, copy and otherwise use the AAM for non-commercial purposes provided that your license is limited by the following restrictions:

(1) You may use this AAM for non-commercial purposes only under the terms of the CC-BY-NC-ND license.

(2) The integrity of the work and identification of the author, copyright owner, and publisher must be preserved in any copy.

(3) You must attribute this AAM in the following format: Creative Commons BY-NC-ND license (http://creativecommons.org/licenses/by-nc-nd/4.0/deed.en), 10.1016/j.cbi.2011.01.011

The publisher's version is available at:

http://linkinghub.elsevier.com/retrieve/pii/S0009279711000160

When citing, please refer to the published version.

Link to this full text:

http://hdl.handle.net/2318/133088 
Importance of Inverse Correlation Between ALDH3A1 and PPAR $\gamma$ in Tumor Cells and Tissue Regeneration.

Oraldi M. ${ }^{1}$, Saracino S. ${ }^{1}$, Maggiora M. ${ }^{1}$, Chiaravalloti A. ${ }^{2,3}$, Buemi C. ${ }^{3}$, Martinasso G. ${ }^{1}$, Paiuzzi E. ${ }^{1}$, Thompson, $\mathrm{D}^{4}$, Vasiliou V, ${ }^{5}$ and Canuto R.A. ${ }^{1}$

${ }^{1}$ Dipartimento di Medicina ed Oncologia Sperimentale, Corso Raffaello 30, 10125 Turin, Italy.

${ }^{2}$ Dipartimento di Meccanica, Politecnico di Torino, Turin, Italy

${ }^{3}$ R\&D DIPRO MEDICAL DEVICES, San Mauro Torinese, Turin, Italy,

${ }^{4}$ Department of Clinical Pharmacy, University of Colorado Denver, Aurora, CO 80045, USA

5 Department of Pharmaceutical Sciences, University of Colorado Denver, Aurora, CO 80045 , USA

Corresponding author:

Prof. Rosa Angela Canuto

Università degli Studi di Torino

Dipartimento di Medicina ed Oncologia Sperimentale

Corso Raffaello 30, 10125 TORINO

Phone: 0039011 6707781; Fax: 0039011 6707753; e-mail: rosangela.canuto@unito.it 
Abstract

Aldehyde dehydrogenase (ALDH) enzymes are involved in maintaining cellular homeostasis by metabolizing both endogenous and exogenous reactive aldehydes. They modulate several cell functions including proliferation, differentiation, survival as well as cellular response to oxidative stress. We previously reported that ALDH3A1 expression is inversely correlated with the activation of PPAR (Peroxisome Proliferators-Activated Receptor), a category of orphan nuclear hormone receptors, in both rat and human cells. PPAR $\gamma$ is involved in cell proliferation. In this study, we have used PPAR $\gamma$ transfection and inhibition to examine the relationship between ALDH3A1 and PPAR $\gamma$ and their role as regulators of cell proliferation. Induction of PPAR $\gamma$ in A549 and NCTC 2544 cells by transfection caused a decrease in ALDH3A1 and inhibition of cell proliferation, a result we obtained previously using ligands that induce PPAR $\gamma$. A reduction of PPAR $\gamma$ expression using siRNA increased ALDH3A1 expression and cell proliferation. In cells induced to proliferate in a model of tissue regeneration, ALDH3A1 expression increased during the period of proliferation, whereas PPAR $\gamma$ expression decreased. In conclusion, through modulation of PPAR $\gamma$ or ALDH3A1, it may be possible to reduce cell proliferation in tumor cells or stimulate cell proliferation in normal cells during tissue regeneration.

Keywords: ALDH3A1, PPAR $\gamma$, tumor cells, tissue regeneration 


\section{Introduction}

Enzymes belonging to aldehyde dehydrogenase (ALDH) family are involved in maintaining cellular homeostasis through the metabolism of both endogenous and exogenous reactive aldehydes $[1,2]$. In this way, they modulate several cell functions, such as proliferation, differentiation, survival and response to oxidative stress in normal and tumor cells [3-8]. Recently, the correlation between ALDH activity and cell proliferation has been documented in several types of stem cells $[9,10]$. For example, human progenitor cells with high ALDH activity more effectively engraft into damaged mouse livers, improving recovery from toxic insult [11]. Among human ALDH isoenzymes, ALDH1A1 is considered a specific marker for both normal and cancer stem cells [12$14]$.

Another member of ALDH family is ALDH3A1 (ALDH; EC 1.2.1.3) that is a homodimer constitutively expressed in various tissues, including cornea, stomach, esophagus and lung, whereas it is induced in several neoplastic tissues [2]. We previously demonstrated that, during chemicallyinduced hepatocarcinogenesis in rat and in a variety of tumor cell lines, transformed cells show increased ALDH3A1 expression that appears coupled to proliferation $[15,16]$. ALDH3A1 has a cytosolic location, and it is also present in the nucleus, where it may exert cell cycle regulation.

This enzyme catalyzes the oxidation of various lipid peroxidation-derived aldehydes including $\alpha \beta$ hydroxyalkenals such as 4-hydroxynonenal. Moreover, ALDH3A1 oxidizes oxazaphosphorines such as cyclophosphamide, contributing to drug resistance in various tumor types [2].

In light of above-described role of ALDHs in cell proliferation, modulation of signal transduction pathways involved in regulating its expression could be crucial in both normal and pathological conditions. We previously reported that ALDH3A1 expression is correlated with PPAR (Peroxisome Proliferators-Activated Receptors) activation in both rat and human cells [1719]. PPARs are orphan nuclear hormone receptors belonging to the nuclear receptor superfamily. Three mammalian PPAR subtypes have been documented, viz. PPAR $\alpha, \operatorname{PPAR} \beta / \delta, \operatorname{PPAR} \gamma$. All exhibit distinct patterns of tissue distribution and are involved in multiple distinctive, often 
complementary, physiologic pathways and functions [20-22]. PPAR $\gamma$ directly regulates a large number of target genes that mediate gluconeogenesis, lipid uptake, lipid synthesis, lipid storage and lipolysis [23-25]. We previously demonstrated that this isotype also modulates other cell functions, such as proliferation. In the presence of PPAR $\gamma$ ligands, a time- and dose-dependent decrease in cell proliferation coupled with decreased ALDH3A1 expression and activity was observed [17-19].

There are several mechanisms by which PPAR $\gamma$ could affect ALDH3A1 expression. PPAR

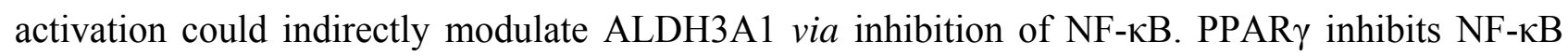
transcriptional activity by binding to the NF- $\mathrm{B}$ components $\mathrm{p} 50$ and $\mathrm{p} 65[26,27]$ and ALDH3A1 gene contains several NF- $\kappa$ B and AP-1 binding sites in its promoter region $[28,29]$. PPAR $\gamma$ could directly modulate ALDH3 expression, since a putative peroxisome proliferator response sequence (PPRE) containing the canonical DR1 motif was found in intron 11 of ALDH3A1 gene using a bioinformatics approach (PROGRAM NHR SCAN) (unpublished data).

In this study, we have used PPAR $\gamma$ transfection and inhibition to examine the relationship between ALDH3A1 and PPAR $\gamma$ and their potential as markers and regulators of cell proliferation in healthy and diseased tissue.

2. Materials and methods

\subsection{Cell cultures}

A549 human lung adenocarcinoma cells (ATCC, USA) were cultured in HAM F-12K medium supplemented with $2 \mathrm{mM}$ glutamine, $1 \%$ (v/v) antibiotic/antimycotic solution and 10\% (v/v) fetal bovine serum (FBS). NCTC 2544 human keratinocytes (ICLC, Italy) were cultured in MEM medium supplemented with $2 \mathrm{mM}$ glutamine, 1\% (v/v) antibiotic/antimycotic solution and $10 \%(\mathrm{v} / \mathrm{v})$ fetal bovine serum (FBS). All cells were maintained at $37^{\circ} \mathrm{C}$ in a humidified atmosphere of $5 \% \mathrm{CO}_{2}$ in air.

\subsection{Transient Transfection Assay}


A549 and NCTC 2544 cells were seeded at $2.5 \times 10^{5}$ cells/well in 6-well plates and allowed to grow to $70 \%$ confluence. Transfections were performed using the cationic polymer reagent ExGen 500 (Fermentas Life Sciences, Germany) according to the instructions of the manufacturer. Cells were transfected with 3 or $5 \mu \mathrm{g}$ of expression vector (pSG5) for human PPAR $\gamma$ (a gift from CIG of Lausanne, Switzerland) or $3 \mu \mathrm{g}$ of pSV- $\beta$-galactosidase (Promega, USA) as a control for transfection efficiency. Twenty-four hr after transfection, the medium was replaced with fresh medium. Twenty-four or $48 \mathrm{hr}$ thereafter, cells were washed with PBS, trypsinized, and centrifuged at $600 \mathrm{~g}$ for $10 \mathrm{~min}$ for the assays (listed below).

\subsection{Treatment with PPAR $\gamma$ antagonist}

A549 and NCTC 2544 cells were seeded in $25-\mathrm{cm}^{2}$ plates at $25,000 \mathrm{cell} / \mathrm{cm}^{2}$. Twenty-four $\mathrm{hr}$ after cell seeding, culture medium was supplemented with PPAR $\gamma$ antagonist (10 $\mu \mathrm{M}$ GW9662) dissolved in DMSO (maximum final concentration $0.05 \%$ ) or an equivalent volume of antagonist vehicle. Forty-eight hr thereafter, cells were washed with PBS trypsinized, and centrifuged at $600 \mathrm{~g}$ for $10 \mathrm{~min}$ for the assays (listed below).

\subsection{PPAR $\gamma$ silencing by small RNA interference}

RNA interference experiments to suppress PPAR $\gamma$ expression were performed using FlexiTube siRNA Premix (Qiagen, Italy). The following target sequence was used: 5'GAGGGCGATCTTGACAGGAAA-3'. The siRNA and negative control were transfected into NCTC 2544 cells, seeded at $1.5 \times 10^{5}$ cells/well in 12-well plates, according to the manufacturer's instructions. Twenty-four hr later, cells were washed with PBS, trypsinized and centrifuged at $600 \mathrm{~g}$ for $10 \mathrm{~min}$ for the assays (listed below).

2.5. Colonization by NCTC 2544 cells of polypropylene mesh prosthesis in a composite form

NCTC 2544 cells were seeded at $1 \times 10^{5}$ cells/well in 6-well plates. A piece of polypropylene composite mesh was anchored to the bottom of each well with a small biologicallyinert sterile sticker to serve as a prosthesis. Composite mesh prosthesis (R\&D DIPRO medical devices, Italy) provides a smooth, non-erosive, anti-adhesive side and a macroporous side that 
allows cell ingrowth. After 3 and $6 \mathrm{~d}$, cells were detached from prosthesis by trypsinization and centrifuged at $600 \mathrm{~g}$ for $10 \mathrm{~min}$ for the assays (listed below).

2.6. Cell growth assay

Cell growth was determined by counting the number of cells using a Bürker chamber.

2.7. Western blot analysis and ALDH enzymatic activity assays

Collected cells were suspended in lysis buffer $\left(10^{6}\right.$ cells/ $\left.50 \mu \mathrm{l}\right)$ containing $0.02 \mathrm{M}$ Tris-HCl (pH 7.4), 0.15 M NaCl, 5 mM EDTA, 1 mM PMSF, $15 \mu \mathrm{g} / \mathrm{ml}$ leupeptin, 0.1\% NP-40 substitute, and $1 \mathrm{mM}$ Na-orthovanadate. Suspensions were kept on ice for $30 \mathrm{~min}$ and sonicated three times for $3 \mathrm{~s}$ using a Branson Sonifier 250 (VWR Scientific, OH, USA). Levels of ALDH3A1, PPAR $\gamma$, GAPDH, and $\beta$-actin were determined by Western blot analysis, as previously described [17]. Polyclonal antiPPAR $\gamma$, anti-GAPDH (purchased from Santa-Cruz Biotechnology Inc., CA, USA), monoclonal anti$\beta$-actin (purchased from Sigma, MO, USA) or anti-ALDH3A1 (prepared by Vasiliou V.) antibodies were used. ALDH activity was determined as described by Canuto et al. [16] using $2.5 \mathrm{mM}$ benzaldehyde as substrate and $\mathrm{NADP}^{+}$as coenzyme.

\subsection{Real-Time PCR}

Total RNA was isolated from NCT 2544 keratinocytes using a RNEasy1 Mini Kit (Qiagen, $\mathrm{GmbH}$, Germany) according to the manufacturer's protocol. One $\mu \mathrm{g}$ of RNA was reverse transcribed in cDNA using the High Capacity cDNA Archive kit (Applied Biosystems, Foster City, CA). PCR was performed using IQTM SYBRGreen Supermix (Bio-Rad, Hercules, CA) in an iCycler system (Bio-Rad). Each sample was tested three times and the threshold cycle $(\mathrm{Ct})$ values from each reaction were averaged. The change was quantified as the relative expression compared to that of control, calculated as $2^{-\Delta \Delta \mathrm{Ct}}$, where $\Delta \mathrm{Ct}=(\mathrm{Ct}$ sample $-\mathrm{Ct}$ GAPDH $)$ and $\Delta \Delta \mathrm{Ct}=(\Delta \mathrm{Ct}$ sample - $\Delta \mathrm{Ct}$ control). Human primer sequences used for real-time PCR were: GAPDH, FW) GTCGGAGTCAACGGATTtGG， RV) GGGTGGAATCATATTGGAACATG; PPAR $\gamma$, FW) GCCGAGAAGGAGAAGC, RV) TGGTCAGCGGGAAGG; ALDH3A1, FW) GTACATGATCCAGAAGC, RV) ATGGTGAGGTTGAAGG. 


\subsection{Light microscope analysis}

Medium was removed from each well containing prostheses colonized by NCTC 2544 cells to observe the colonization by light microscope.

\subsection{Protein determination}

Protein content was determined with the Protein Assay Kit 2 (BIO-RAD, Laboratories, CA).

\subsection{Statistical analysis}

Data are expressed as means \pm S.D. Differences between group means were assessed by analysis of variance, followed by post-hoc Newman-Keuls analysis. The effect of PPAR $\gamma$ antagonist treatment, or of time on prosthesis were assessed by Student's unpaired t-test. $\mathrm{P}<0.05$ was considered to be significant.

3. Results and discussion

3.1 Inverse correlation between ALDH3A1 and PPAR $\gamma$ in human lung tumor and normal cells.

In our previous studies carried out in human tumor cells, we showed that ligands of PPAR $\gamma$, such as arachidonic and docosahexaenoic acids, decreased cell proliferation with coincident induction of PPAR $\gamma$ and decrease in ALDH3A1 expression and activity [19,30]. To examine further the inverse correlation between these two factors, two different approaches were taken: induction or inhibition of PPAR $\gamma$. PPAR $\gamma$ induction was achieved through PPAR $\gamma$ transfection. Inhibition of PPAR $\gamma$ was obtained by using a selective antagonist, GW9662, or a siRNA method. Experiments were conducted in two different cell lines: lung tumor cells (A459) and normal keratinocytes (NCTC 2544).

\subsubsection{PPAR $\gamma$ transfection.}

A459 and NCTC 2544 cells that were transfected with plasmid SG5 containing cDNA of PPAR $\gamma$ grew more slowly than control cells (Figure 1). The culture medium was also evaluated for the cells detached from the monolayer, but no cells were counted in it (data not shown)]. As 
expected, higher levels of PPAR $\gamma$ protein were observed in cells transfected with plasmid SG5 containing cDNA of PPAR $\gamma$ (Figure 2). Expression of ALDH3A1 protein revealed opposite behaviour in being reduced in these same cells (Figure 2). These results are consistent with our previous results in which specific ligands were used to induce PPAR $\gamma[19,30]$ and support the proposal that induction of PPAR $\gamma$ causes a decrease of ALDH3A1 with the consequent inhibition of cell proliferation.

\subsubsection{PPAR $\gamma$ inhibition.}

An inverse relationship between PPAR $\gamma$ expression and ALDH3A1 and cell proliferation was established in the above experiments using the transfection to manipulate PPAR $\gamma$ levels. Experiments using the PPAR $\gamma$ antagonist, GW9662, provided equivocal results. GW9662 treatment had no effect on cell proliferation (Figure 3A) or on PPAR $\gamma$ expression (Figure 3B). However, GW9662 treatment caused an increase in ALDH3A1 protein expression (Figure 4A) that was not accompanied by a significant increase of specific ALDH3A1 activity (Figure 4B). Small RNA interference was used as another approach to reduce PPAR $\gamma$ effects. In these experiments, PPAR $\gamma$ expression was suppressed in keratinocytes. This intervention increased cell proliferation (Figure 5A), decreased PPAR $\gamma$, evaluated as mRNA (Figure 5B) and protein content (Figure 5C), and increased ALDH3A1, evaluated also as mRNA (Figure 5B) and protein content (Figure 5C). These results would have been predicted from our PPAR $\gamma$ transfection results. It is difficult to rationalize the different results obtained with PPAR $\gamma$ antagonist and gene silencing. The failure of GW9662 to affect cell proliferation may have occurred if the concentrations of the antagonist were insufficient. However, the concentration utilized in the present study is comparable with those shown to be effective in other studies [19].

3.2. ALDH3A1 and PPAR $\gamma$ in tissue regeneration.

In the light of above results, it is conceivable that ALDH3A1 and PPAR $\gamma$ could function to modulate cell proliferation. For example, proliferation could be stimulated by increasing ALDH or inhibiting PPAR $\gamma$, as noted above. To further examine their physiological roles in cell proliferation, 
changes in expression were examined in a model of tissue regeneration. Keratinocytes were grown on a composite mesh prosthesis. The scaffold of the prosthesis serves as a support upon which seeded cells colonize, migrate and grow [31,32]. In this model, cells attached and grew on the mesh prosthesis (Figure 6A). Over the course of $6 \mathrm{~d}$, cells continued to grow (Figure 6B). Consistent with the results obtained in normal tissue culture plates, ALDH3A1 protein expression increased over time while PPAR $\gamma$ protein content decreased (Figure 6C). Therefore, PPAR $\gamma$ and ALDH3A1 could be considered as markers of cell proliferation. Furthermore, manipulation of the activity or effects of these molecules may be a novel approach for promoting cell proliferation, e.g., by stimulating ALDH activity through the application of an activator [33,34]. Should this prove to be effective, such treatments could be used to promote tissue repair or regeneration. Conversely, inhibition of ALDH3A1 or activation of PPAR $\gamma$ may be used to suppress cell proliferation, e.g., to elicit an antitumor effect.

\section{Conclusions}

Using overexpression, gene silencing and antagonist inhibition to modulate the expression or effects of PPAR $\gamma$, the present study demonstrated that ALDH3A1 expression is inversely regulated by PPAR $\gamma$ and ALDH3A1 expression is directly correlated with cell proliferation. Therefore, modulation of PPAR $\gamma$ or ALDH3A1 may be a novel approach to manipulate cell proliferation and provide benefit in the treatment of cancer or tissue repair.

\section{Acknowledgments.}

This research was supported by grants from CIPE-NABLA project, Regione Piemonte, Italy, from the University of Turin, Italy and NIH EY17963. We thank CIG of Lausanne (Switzerland) for providing us the PPAR $\gamma$ plasmid. O. M. was supported by USPHS NIH grant R13-AA019612 to present this work at the 15th International Meeting on Enzymology and Molecular Biology of 
Carbonyl Metabolism in Lexington, KY USA. 


\section{References}

[1] W.K. Harvey, R. Lindahl, Activity of various aldehyde-metabolizing enzymes in chemicallyinduced rat hepatomas. Biochem. Pharmacol. 31 (1982) 1153-1155.

[2] S.A. Marchitti, C. Brocker, D. Stagos, V.Vasiliou, Non-P450 aldehyde oxidizing enzymes: the aldehyde dehydrogenase superfamily. Expert. Opin. Drug. Metab. Toxicol. 4 (2008) 697720.

[3] N.E. Sládek, Human aldehyde dehydrogenases: potential pathological, pharmacological, and toxicological impact. J. Biochem. Mol. Toxicol.17 (2003) 7-23.

[4] J.S. Moreb, H.V. Baker, L.J. Chang, M. Amaya, M.C. Lopez, B. Ostmark, W. Chou, ALDH isozymes downregulation affects cell growth, cell motility and gene expression in lung cancer cells. Mol. Cancer 7 (2008) 87.

[5] R.A. Canuto, M. Ferro, M. Maggiora, R. Federa, O. Brossa, A.M. Bassi, R. Lindahl, G. Muzio, In hepatoma cell lines restored lipid peroxidation affects cell viability inversely to aldehyde metabolizing enzyme activity. Adv. Exp. Med. Biol. 414 (1997) 113-122.

[6] G. Barrera, S. Pizzimenti, G. Muzio, M. Maggiora, A. Garramone, F. Biasi, M.U. Dianzani, R.A. Canuto, Enzymatic pattern of aldehyde metabolism during HL-60 cell differentiation. Biochem. Biophys. Res. Commun. 223(1996) 73-79.

[7] T. Estey, J. Piatigorsky, N. Lassen, V. Vasiliou, ALDH3A1: a corneal crystallin with diverse functions. Exp. Eye Res. 84(2007):3-12.

[8] W.J. Black, D. Stagos, S.A. Marchitti, D.W. Nebert, K.F. Tipton, A. Bairoch, V. Vasiliou, Human aldehyde dehydrogenase genes: alternatively spliced transcriptional variants and their suggested nomenclature. Pharmacogenet. Genomics. 19(2009) 893-902.

[9] T.J. Povsic, K.L. Zavodni, F.L. Kelly, S. Zhu, P.J. Goldschmidt-Clermont, C. Dong, E.D. Peterson, Circulating progenitor cells can be reliably identified on the basis of aldehyde dehydrogenase activity. J. Am. Coll. Cardiol. 50 (2007) 2243-2248. 
[10] D.J. Pearce, D. Bonnet, The combined use of Hoechst efflux ability and aldehyde dehydrogenase activity to identify murineand human hematopoietic stem cells. Exp. Hematol. 35 (2007) 1437-1446.

[11] P. Zhou, S. Hohm, Y. Olusanya, D.A. Hess, J. Nolta, Human progenitor cells with high aldehyde dehydrogenase activity efficiently engraft into damaged liver in a novel model. Hepatology 49 (2009) 1992-2000.

[12] E.H. Huang, M.J. Hynes, T. Zhang, C. Ginestier, G. Dontu, H. Appelman, J.Z. Fields, M.S. Wicha, B.M. Boman, Aldehyde dehydrogenase 1 is a marker for normal and malignant human colonic stem cells (SC) and tracks SC overpopulation during colon tumorigenesis. Cancer Res. 69 (2009) 3382-3389.

[13] C. Ginestier, M.H. Hur, E. Charafe-Jauffret, F. Monville, J. Dutcher, M. Brown, J. Jacquemier, P. Viens, C.G. Kleer, S. Liu, A. Schott, D. Hayes, D. Birnbaum, M.S. Wicha, G. Dontu, ALDH1 is a marker of normal and malignant human mammary stem cells and a predictor of poor clinical outcome. Cell Stem Cell 1 (2007) 555-567.

[14] J. Douville, R. Beaulieu, D. Balicki, ALDH1 as a functional marker of cancer stem and progenitor cells. Stem Cells Dev. 18 (2009) 17-26.

[15] R.A. Canuto, G. Muzio, M.E. Biocca, M.U. Dianzani, Oxidative metabolism of 4-hydroxy2,3-nonenal during diethyl-nitrosamine-induced carcinogenesis in rat liver. Cancer Lett. 46(1989) 7-13.

[16] R.A. Canuto, M. Ferro, G. Muzio, A.M. Bassi, G. Leonarduzzi, M. Maggiora, D. Adamo, G. Poli and R. Lindahl, Role of aldehyde metabolising enzymes in mediating effects of aldehyde products of lipid peroxidation in liver cells. Carcinogenesis 15 (1994) 1359-1364.

[17] R.A. Canuto, M. Ferro, R.A. Salvo, A.M. Bassi, A. Trombetta, M. Maggiora, G. Martinasso, R. Lindahl, G. Muzio, Increase in class 2 aldehyde dehydrogenase expression by arachidonic acid in rat hepatoma cells. Biochem. J. 357(2001) 811-818. 
[18] R.A. Canuto, M. Maggiora, A. Trombetta, G. Martinasso, G. Muzio, Aldehyde dehydrogenase 3 expression is decreased by clofibrate via PPAR gamma induction in JM2 rat hepatoma cell line. Chem. Biol. Interact. 143-144 (2003) 29-35.

[19] G. Muzio, A. Trombetta, M. Maggiora, G. Martinasso, V. Vasiliou, N. Lassen, R.A. Canuto, Arachidonic acid suppresses growth of human lung tumor A549 cells through downregulation of ALDH3A1 expression. Free Radic. Biol. Med. 40(2006) 1929-1938.

[20] W. Wahli, O. Braissant, B. Desvergne, Peroxisome proliferator activated receptors: transcriptional regulators of adipogenesis, lipid metabolism and more. Chem. Biol. 2 (1995) $261-266$

[21] B. Desvergne, W. Wahli, PPAR: a key nuclear factor in nutrient/gene interactions? In: P. Bauerle (Ed.), Inducible transcription, Birkhauser Boston (MA), 1995. vol. 1, pp. 142-176.

[22] A. Chawla, J.J. Repa, R.M. Evans, D.J. Mangelsdorf, Nuclear receptors and lipid physiology: opening the X-files. Science 294 (2001) 1866-1870.

[23] S.I. Anghel, and W. Wahli, Fat poetry: a kingdom for PPARgamma. Cell Res. 17 (2007) 486511.

[24] P. Tontonoz, and B.M. Spiegelman, Fat and beyond: the diverse biology of PPARgamma. Annu. Rev. Biochem. 77 (2008) 289-312.

[25] R. Nielsen, T.A. Pedersen, D. Hagenbeek, P. Moulos, R. Siersbaek, E. Megens, S. Denissov, M. Børgesen, K.J. Francoijs, S. Mandrup, H.G. Stunnenberg, Genome-wide profiling of PPARgamma: RXR and RNA polymerase II occupancy reveals temporal activation of distinct metabolic pathways and changes in RXR dimer composition during adipogenesis. Genes Dev. 22 (2008) 2953-2967.

[26] S.W. Chung, B.Y. Kang, S.H. Kim, Y.K. Pak, D. Cho, G. Trinchieri and T.S. Kim, Oxidized low density lipoprotein inhibits interleukin-12 production in lipopolysaccharide-activated mouse macrophages via direct interactions between peroxisome proliferator-activated receptor-gamma and nuclear factor-kappa B. J. Biol. Chem. 275 (2000) 32681-32687. 
[27] F. Chen, M. Wang, J.P. O'Connor, M. He, T. Tripathi and L.E. Harrison, Phosphorylation of PPARgamma via active ERK1/2 leads to its physical association with p65 and inhibition of NF-kappabeta. J. Cell. Biochem. 90 (2003) 732-744.

[28] V. Vasiliou, S.F. Reuter, S. Williams, A. Puga and D.W. Nebert, Mouse cytosolic class 3 aldehyde dehydrogenase (Aldh3a1): gene structure and regulation of constitutive and dioxininducible expression. Pharmacogenetics 9 (1999) 569-580.

[29] Y.Q. Xie, K. Takimoto, H.C. Pitot, W.K. Miskimins and R. Lindahl, Characterization of the rat Class 3 aldehyde dehydrogenase gene promoter. Nucleic Acids Res. 24 (1996) 4185-4191.

[30] R.A. Canuto, M. Maggiora, G. Martinasso, M. Oraldi, V. Vasiliou, A.Trombetta, and G. Muzio, ALDH3A1 Expression Is Modulated by Docosahexaenoic Acid through Peroxisome Proliferator-Activated Receptors (PPARs) in Human Lung Adenocarcinoma Cells. In: H. Weiner, E. Maser, R. Lindahl, B. Plapp (Ed.), Enzymology and Molecular Biology of Carbonyl Metabolism 13, Purdue University Press, West Lafayette, Indiana, USA, 2007. pp. 91-98.

[31] K.F. Leong, C.M. Cheah, C.K. Chua, Solid freefom fabrication of three-dimensional scaffolds for engineering replacement tissues and organs. Biomaterials 24 (2003) 236-2378.

[32] C. Vitale-Brovarone, E. Verné, L. Robiglio, G. Martinasso, R.A. Canuto, G. Muzio, Biocompatible glass-ceramic materials for bone substitution. J. Mater. Sci. Mater. Med. 19 (2008) 471-478.

[33] S. Perez-Miller, H. Younus, R. Vanam, C.H. Chen, D. Mochly-Rosen, T.D. Hurley, Alda-1 is an agonist and chemical chaperone for the common human aldehyde dehydrogenase 2 variant. Nat. Struct. Mol. Biol. 17 (2010) 159-164.

[34] C.H. Chen, L. Sun, D. Mochly-Rosen, Mitochondrial aldehyde dehydrogenase and cardiac diseases. Cardiovasc. Res. 2010 [Epub ahead of print]. 
Figure Captions

Figure 1

Inhibition of cell proliferation by transfection of cells with pSG5 containing PPAR $\gamma$. Human lung tumor cells (A549) and keratinocytes (NCTC 2544) were transfected with 3 or $5 \mu \mathrm{g}$ pSG5 with PPAR $\gamma$ (PPARgamma 3, PPARgamma 5, respectively) or pSV- $\beta$-galactosidase (C) and harvested for cell counting 24 or $48 \mathrm{hr}$ later. Data are represented as means \pm S.D. from 3 experiments. For each type of cells and for 24 or 48 hours, means with different letters are significantly different from one another $(\mathrm{p}<0.05)$ as determined by analysis of variance followed by post-hoc NewmanKeuls analysis.]

Figure 2

Effect of transfection with pSG5 containing PPAR $\gamma$ on PPAR $\gamma$ and ALDH3A1 protein expression. Human lung tumor cells (A549) and keratinocytes (NCTC 2544) were transfected with 3 or $5 \mu \mathrm{g}$ pSG5 with PPAR $\gamma(\gamma \mathbf{3}, \gamma \mathbf{5}$, respectively) or pSV- $\beta$-galactosidase $(\mathbf{C})$ and harvested for Western blot analysis of PPAR $\gamma$ and ALDH3A1 protein content 24 or $48 \mathrm{hr}$ later. With regard to PPAR $\gamma$, both isoforms PPAR $\gamma 1$ and $\gamma 2$ were detected by polyclonal antibody. The densitometry value given for each protein is referred to the corresponding $\beta$-actin value and expressed by arbitrarily normalizing the control value as 100 . The densitometry values of PPAR $\gamma 1$ were not calculated, being 0 the control value.

$\mathrm{C}+$, positive control for ALDH3A1

Figure 3

Failure of PPAR $\gamma$ antagonist to affect cell proliferation or PPAR $\gamma$ expression. Human lung tumor cells (A549) and keratinocytes (NCTC 2544; NCTC) were treated with PPAR $\gamma$ antagonist $(10 \mu \mathrm{M}$ 
GW9662; GW) or an equivalent volume of vehicle (C) for $48 \mathrm{hr}$. Cells were then harvested for cell counting (panel A) or Western blot analysis of PPAR $\gamma$ (panel B). The number of cells $/ \mathrm{cm}^{2}$ counted in the monolayer (panel A) are represented as means \pm S.D. from 3 experiments. The densitometry value given for each protein is referred to the corresponding $\beta$-actin value and expressed by arbitrarily normalizing the control value as 100 .

Figure 4

Modulation of ALDH3A1 expression and activity by a PPAR $\gamma$ antagonist. Human lung tumor cells (A549) and keratinocytes (NCTC 2544; NCTC) were treated with PPAR $\gamma$ antagonist $(10 \mu \mathrm{M}$ GW9662; GW) or an equivalent volume of vehicle (C) for $48 \mathrm{hr}$. Cells were then harvested for measurement of Western blot analysis of ALDH3A1 (panel A) or ALDH3A1 specific activity (panel B). The densitometry value given for each protein is referred to the corresponding $\beta$-actin value and expressed by arbitrarily normalizing the control value as 100. Specific activity, determined spectrophotometrically using benzaldehyde as substrate and $\mathrm{NADP}^{+}$as coenzyme, is expressed as nmoles NADP reduced per min per mg protein. Specific activity results are presented as means \pm S.D. from 3 experiments.

$\mathrm{C}+$, positive control for ALDH3A1

\section{Figure 5}

Effect of PPAR $\gamma$ silencing on cell proliferation and PPAR $\gamma$ and ALDH3A1 expression. Human keratinocytes (NCTC 2544) were not transfected (C) or transfected with siRNA to suppress PPAR $\gamma$ expression (PPARgamma-siRNA or $\boldsymbol{\gamma}$ ) or with non-silencing RNA (C-siRNA or C-). Twenty-four hr later, cells were harvested for cell counting (panel A), for real-time PCR of mRNA content for PPAR $\gamma$ or ALDH3A1 (panel B), or western blot analysis of protein content of PPAR $\gamma$ and ALDH3A1 (panel C). The number of cells $/ \mathrm{cm}^{2}$ counted in the monolayer (panel A) are represented 
as means \pm S.D. from 3 experiments. The densitometry value given for each protein is referred to the corresponding $\beta$-actin value and expressed by arbitrarily normalizing the control value as 100 . For cell number, and PPAR $\gamma$ and ALDH3A1 mRNA content, means with different letters are significantly different from one another $(\mathrm{p}<0.05)$ as determined by analysis of variance followed by post-hoc Newman-Keuls analysis.

Figure 6

PPAR $\gamma$ and ALDH3A1 expression in a model of tissue repair. Keratinocytes (NCTC 2544 cells) were seeded on a composite mesh prosthesis. Cells were then harvested for counting (panel B) or Western blot analysis of PPAR $\gamma$ and ALDH3A1 (panel C) at 3 and 6 days after cell seeding. Panel A shows the cells grown on composite mesh at 3 days evaluated by light microscopy. Total cell numbers are presented as means \pm S.D. from 3 experiments. The densitometry value given for each protein is referred to the corresponding $\beta$-actin value and expressed by arbitrarily normalizing the control value as 100 .

$\mathrm{C}+$, positive control for ALDH3A1

* $\mathrm{P}<0.05$, compared to number of cells at day 3 , Student's unpaired t-test. 


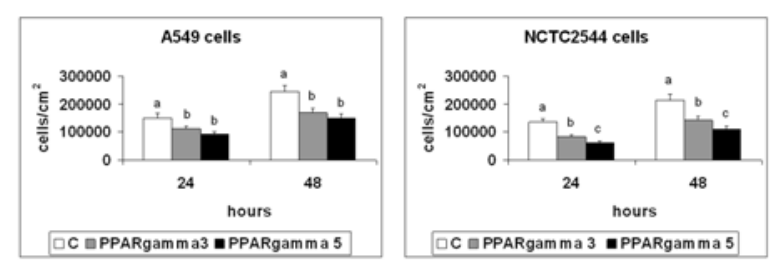


Figure 2

\section{A549 cells}
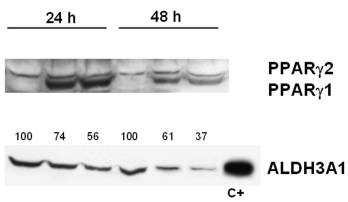

$\beta$-actin

$$
\text { C } \gamma 3 \gamma 5 \text { C } \gamma 3 \gamma 5
$$

\section{NCTC 2544 cells}
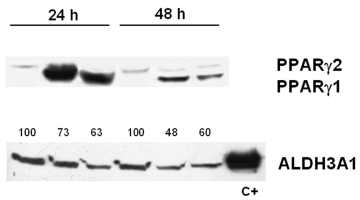

$\beta$-actin 


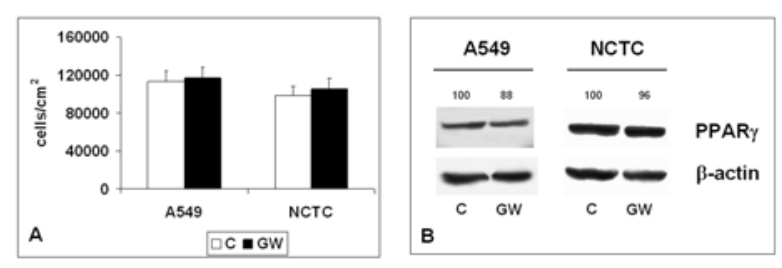


Figure 4
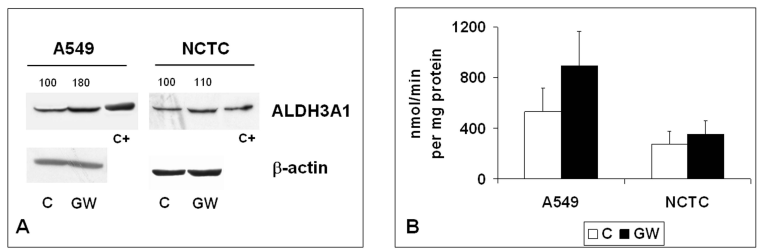
